09,08

\title{
Люминофоры холодного голубого излучения на основе оксида алюминия, допированного диспрозием
}

\author{
(C) И.В. Бакланова, В.Н. Красильников, А.П. Тютюнник, Я.В. Бакланова \\ Институт химии твердого тела УрО РАН, \\ Екатеринбург, Россия \\ E-mail: baklanova_i@ihim.uran.ru
}

Поступила в Редакцию 30 августа 2021 г.

В окончательной редакции 30 августа 2021 г.

Принята к публикации 3 сентября 2021 г.

По прекурсорной технологии были синтезированы оксиды $\mathrm{Al}_{2} \mathrm{O}_{3}: \mathrm{Dy}^{3+}$ различных цветов свечения. Рентгеноструктурным анализом установлены фазовый состав и структура, полученных материалов. Исследованы спектры возбуждения и эмиссии, кривые затухания, термическое тушение люминесценции. При УФ-возбуждении люминофоры демонстрирует голубую, фиолетово-синюю и белую эмиссию в зависимости от концентрации диспрозия и температуры отжига прекурсора $\mathrm{Al}_{1-x} \mathrm{Dy}_{x}(\mathrm{OH})(\mathrm{HCOO})_{2}$ на воздухе.

Ключевые слова: оксид алюминия, диспрозий, прекурсорный метод синтеза, люминесценция, цветовые координаты.

DOI: 10.21883/FTT.2022.01.51837.196

\section{1. Введение}

Люминесцентные материалы окрашенного и белого свечения являются предметом интенсивных исследований в связи с реальной перспективой применения в производстве светодиодов, жидкокристаллических и плазменных дисплеев, осветительных приборов, радиационных дозиметров и т.д. [1]. Для развития современной оптической и цифровой технологии большое значение приобретает создание люминофоров, позволяющих регулировать цветовые характеристики излучения и обеспечивать требуемую цветовую гамму. Один из наиболее часто применяемых методов настройки цвета излучения основан на рациональном подборе люминесцентных матриц и примесных ионов, эмиссионные спектры которых будут перекрываться друг с другом. В последнее время материалы, излучающие синий или голубой свет, приобрели большое значение в контексте получения люминофоров с белой люминесценцией. Так, путем комбинации синей люминесценции InGaN и желтой $\mathrm{YAG}: \mathrm{Ce}^{3+}$ был впервые получен коммерческий светодиод белого свечения (WLED) [2]. В качестве источников синего излучения кроме InGaN могут быть, например, использованы $\mathrm{ZnS}$ [3], $\mathrm{AWO}_{4}(\mathrm{~A}=\mathrm{Ca}, \mathrm{Sr}$, Ba) [4] и $\mathrm{NaYF}_{4}$ [5], допированные ионами $\mathrm{Tm}^{3+}$, a также $\mathrm{BaMgAl}_{10} \mathrm{O}_{17}$, допированный ионами $\mathrm{Eu}^{2+}$ [6-7]. Однако в ходе эксплуатации описанных [2-7] люминесцентных материалов были выявлены их существенные недостатки. Например, для InGaN/YAG : $\mathrm{Ce}^{3+}$ характерно разделение синего и желтого спектральных диапазонов, а также неудовлетворительная цветопередача, вызванная отсутствием красного компонента спектра. Синие люминофоры $\mathrm{ZnS}: \mathrm{Tm}^{3+}$ отличаются высокой светоотдачей, но химически нестабильны и подвержены термическому гашению люминесценции при относительно низких рабочих температурах [3]. Допирование тулием (III) вольфраматов $\mathrm{AWO}_{4}$ позволяет получить синее излучение при УФ-возбуждении (электронный переход ${ }^{1} \mathrm{D}_{2} \rightarrow{ }^{3} \mathrm{~F}_{4}$ в ионе $\mathrm{Tm}^{3+}$ ), но из-за малого поглощения имеет очень слабое свечение в видимом диапазоне спектра [4]. Повышение эффективности люминесценции ионов $\mathrm{Tm}^{3+}$ в матрице $\mathrm{NaYF}_{4}$ возможно за счет передачи энергии от других ионов, например, $\mathrm{Ce}^{3+}, \mathrm{Eu}^{2+}$ или $\mathrm{Dy}^{3+}$ [5]. Несмотря на высокую интенсивность синего свечения $\mathrm{BaMgAl}_{10} \mathrm{O}_{17}: \mathrm{Eu}^{2+}$ подвержен окислительной деструкции при эксплуатации, связанной с окислением ионов $\mathrm{Eu}^{2+}$ до $\mathrm{Eu}^{3+}$, что постепенно приводит к понижению его люминесцентных характеристик [8]. Кроме того, спектр возбуждения $\mathrm{BaMgAl}_{10} \mathrm{O}_{17}: \mathrm{Eu}^{2+}$ обладает сильным поглощением в коротковолновом и средневолновом УФ-диапазоне и гораздо меньшим в длинноволновом, что совершенно не подходит для изготовления светодиодов. Известны матрицы с голубой люминесценцией, например, $\mathrm{NaCaBO}_{3}$ и $\mathrm{Gd}_{5} \mathrm{Si}_{3} \mathrm{O}_{12} \mathrm{~N}$, активированные ионами церия (III) [9-10]. Замена дорогого европия на относительно дешевый церий дает коммерческий эффект, однако наличие церия в люминесцентных объектах, как и в случае с $\mathrm{Eu}^{2+}$ [6-7], требует особых условий синтеза, препятствующих переходу $\mathrm{Ce}^{3+}{ }_{\text {в }} \mathrm{Ce}^{4+}$. С учетом этого актуальной задачей являются поиск и разработка новых более дешевых люминофоров синеголубого спектра с хорошими эмиссионными характеристиками и стабильных в условиях эксплуатации, синтез которых основан на простых технологических решениях. В предыдущих работах [11-13] нами было показано, что для нанодисперсного оксида алюминия, полученного термообработкой основного формиата алюминия состава $\mathrm{Al}(\mathrm{OH})(\mathrm{HCOO})_{2}$, характерна голубая 
эмиссия с максимум около $450 \mathrm{~nm}$, происхождение которой связано с наличием собственных дефектов решетки и/или примесного углерода. Нанодисперсные оксиды $\mathrm{Al}_{2} \mathrm{O}_{3}: \mathrm{Ln} \quad\left(\mathrm{Ln}=\mathrm{Eu}^{3+} / \mathrm{Tb}^{3+}\right)$ с содержанием допантов $2.5 \mathrm{~mol} \%$ были синтезированы путем термолиза прекурсоров $\mathrm{Al}_{1-x} \operatorname{Ln}_{x}(\mathrm{OH})(\mathrm{HCOO})_{2}$ на воздухе при $700^{\circ} \mathrm{C}[14]$. Рассчитанные цветовые координаты демонстрируют, что цвет их люминесценции близок к белому [15]. Ионный радиус иона $\mathrm{Dy}^{3+}$ меньше радиусов ионов $\mathrm{Eu}^{3+}$ и $\mathrm{Tb}^{3+}$ (Dy ${ }^{3+}(\mathrm{VI}) 0.912 \AA$ ) [16], а в диапазоне 400-760 nm может демонстрировать голубую, желтую и красную люминесценцию иона диспрозия, связанную с f-f-переходами ${ }^{4} \mathrm{~F}_{9 / 2} \rightarrow{ }^{6} \mathrm{H}_{15 / 2},{ }^{4} \mathrm{~F}_{9 / 2} \rightarrow{ }^{6} \mathrm{H}_{13 / 2},{ }^{4} \mathrm{~F}_{9 / 2} \rightarrow{ }^{6} \mathrm{H}_{11 / 2}$. Известно, что электрический дипольный переход ${ }^{4} \mathrm{~F}_{9 / 2} \rightarrow{ }^{6} \mathrm{H}_{13 / 2}$ особенно чувствителен к окружению иона диспрозия в матрице в отличие от магнитного дипольного перехода ${ }^{4} \mathrm{~F}_{9 / 2} \rightarrow{ }^{6} \mathrm{H}_{15 / 2}$ [17]. Когда ион Dy ${ }^{3+}$ занимает в матрице низкосимметричные позиции, желтое излучения люминофора является более доминирующим по сравнении с голубым. Напротив, голубое излучение будет преобладающим при расположении ионов $\mathrm{Dy}^{3+}$ в высокосимметричных позициях. Все эти структурные особенности в итоге сказываются на суммарном цветовом излучении. Сведения по люминесценции $\mathrm{Al}_{2} \mathrm{O}_{3}: \mathrm{Dy}^{3+}$ уже были представлены в ряде работ [18-22], но ни в одной из них не сообщается о вкладе матрицы оксида алюминия в люминесценцию в видимом диапазоне. Публикации в основном связаны с подбором оптимального содержания активатора в матрице $\alpha-\mathrm{Al}_{2} \mathrm{O}_{3}$, не вызывающего концентрационного тушение люминесценции. В настоящей работе представлены структурные, морфологические, оптические и люминесцентные характеристики порошков $\mathrm{Al}_{2} \mathrm{O}_{3}: \mathrm{Dy}^{3+}$ полученных отжигом прекурсоров на воздухе, а также установлено влияние концентрации диспрозия и условий термообработки прекурсора $\mathrm{Al}_{1-x} \mathrm{Dy}_{x}(\mathrm{OH})(\mathrm{HCOO})_{2}$ на цвет излучения люминофора. Возможность дозированного замещения алюминия на лантаноид в структуре прекурсора, а соответственно и в синтезируемом оксиде алюминия является важным преимуществом используемой прекурсорной технологии.

\section{2. Методика эксперимента}

Для получения допированного диспрозием оксида алюминия номинального состава $\mathrm{Al}_{2} \mathrm{O}_{3}$ : $\mathrm{Dy}^{3+}$ была разработана методика прекурсорного синтеза, при которой оксид получали нагреванием на воздухе прекурсора $\mathrm{Al}_{1-x} \mathrm{Dy}_{x}(\mathrm{OH})(\mathrm{HCOO})_{2}$. Синтез $\mathrm{Al}_{1-x} \mathrm{Dy}_{x}(\mathrm{OH})(\mathrm{HCOO})_{2}$ с $x=0.005,0.01,0.02$ и 0.025 был осуществлен по следующей реакции:

$$
\begin{aligned}
(2 & -2 x) \mathrm{Al}\left(\mathrm{NO}_{3}\right)_{3}+2 x \mathrm{Dy}\left(\mathrm{NO}_{3}\right)_{3}+19 \mathrm{HCOOH} \\
& =2 \mathrm{Al}_{1-x} \mathrm{Dy}_{x}(\mathrm{OH})(\mathrm{HCOO})_{2}+3 \mathrm{~N}_{2}+15 \mathrm{CO}_{2}+16 \mathrm{H}_{2} \mathrm{O} .
\end{aligned}
$$

Аналитически чистые нитрат алюминия $\mathrm{Al}\left(\mathrm{NO}_{3}\right)_{3} \cdot 9 \mathrm{H}_{2} \mathrm{O}$, нитрат диспрозия $\mathrm{Dy}\left(\mathrm{NO}_{3}\right)_{3} \cdot 6 \mathrm{H}_{2} \mathrm{O}$ и муравьиная кислота $(99.7 \% \mathrm{HCOOH})$ были применены как реактивы, дистиллированная вода как растворитель. Взятые в стехиометрических количествах согласно химической формуле $\mathrm{Al}_{1-x} \mathrm{Dy}_{x}(\mathrm{OH})(\mathrm{HCOO})_{2}$ нитраты алюминия и диспрозия растворяли в разбавленной муравьиной кислоте $(20 \%)$ при комнатной температуре. Упаривание раствора проводили при $60^{\circ} \mathrm{C}$ до сухого остатка в виде белого порошка, который перетирали в фарфоровой ступке. Для получения оксидов прекурсоры $\mathrm{Al}_{1-x} \mathrm{Dy}_{x}(\mathrm{OH})(\mathrm{HCOO})_{2}$ нагревали при 700, 900 и $1100^{\circ} \mathrm{C}$ на воздухе в течение двух часов. Рентгенофазовый анализ синтезированных образцов осуществляли с помощью дифрактометра STADI-P (STOE), оснащенного линейным позиционно-чувствительным детектором. Съемка проводилась в $\mathrm{CuK}_{\alpha 1}$ излучении в интервале углов $2 \theta$ от 5 до $120^{\circ}$ с шагом $0.02^{\circ}$. В качестве внешнего стандарта использовали поликристаллический кремний ( $a=5.43075(5) \AA)$. Идентификация фаз проведена с использованием картотеки PDF2 (ICDD, 2016). Уточнение кристаллических структур соединений проведено методом полнопрофильного анализа Ритвельда с использованием программного пакета GSAS [23-24]. КР-спектр был зарегистрирован при комнатной температуре с использованием конфокального Рамановского микроскопа Renishaw InVia Reflex $(\lambda=532 \mathrm{~nm}, P=5 \mathrm{~mW})$. Термический анализ осуществляли на термоанализаторе Netzsch STA 449 F3 Jupiter при нагревании на воздухе со скоростью $10 \% \mathrm{~min}$. Регистрация спектров возбуждения и люминесценции, кривых затухания была осуществлена с помощью флуориметра Varian Cary Eclipse (Хе лампа). Спектры люминесценции в диапазоне температур от 25 до $150^{\circ} \mathrm{C}$ записаны с использованием температурноконтролируемой ячейки GS-21525 (Specac Ltd).

\section{3. Экспериментальные результаты и их обсуждение}

На примере $\mathrm{Al}_{1-x} \mathrm{Dy}_{x}(\mathrm{OH})(\mathrm{HCOO})_{2}$ с содержанием диспрозия $2 \mathrm{~mol} . \% \quad(x=0.02) \quad$ было показано, что синтезированные согласно реакции (1) прекурсоры структурно идентичны гидроксоформиату алюминия $\mathrm{Al}(\mathrm{OH})(\mathrm{HCOO})_{2} \quad[25]$. Дифрактограмма $\mathrm{Al}_{0.98} \mathrm{Dy}_{0.02}(\mathrm{OH})(\mathrm{HCOO})_{2}$ (рис. 1) была индицирована в моноклинной сингонии (пространственная группа $C 2$ ) с параметрами элементарной ячейки: $a=8.900(2) \AA$, $b=9.955(3) \AA, \quad c=10.262(2) \AA, \quad \beta=106.41(1)^{\circ}, \quad V=$ $=872.2(4) \AA^{3}$.

Формирование диспрозий-замещенного гидроксоформиата $\mathrm{Al}_{1-x} \mathrm{Dy}_{x}(\mathrm{OH})(\mathrm{HCOO})_{2}$ со структурой $\mathrm{Al}(\mathrm{OH})(\mathrm{HCOO})_{2}$ подтверждается данными КР-спектроскопии (рис. 2) [13,14,25]. Частота $1068 \mathrm{~cm}^{-1}$ отвечает за внеплоскостные деформационные колебания связи $\mathrm{C}-\mathrm{H}$. Валентные колебания связей $\mathrm{C}-\mathrm{H}$ фиксируются при 2922, 2937, 2978 и $3015 \mathrm{~cm}^{-1}$. Линия $784 \mathrm{~cm}^{-1}$ 


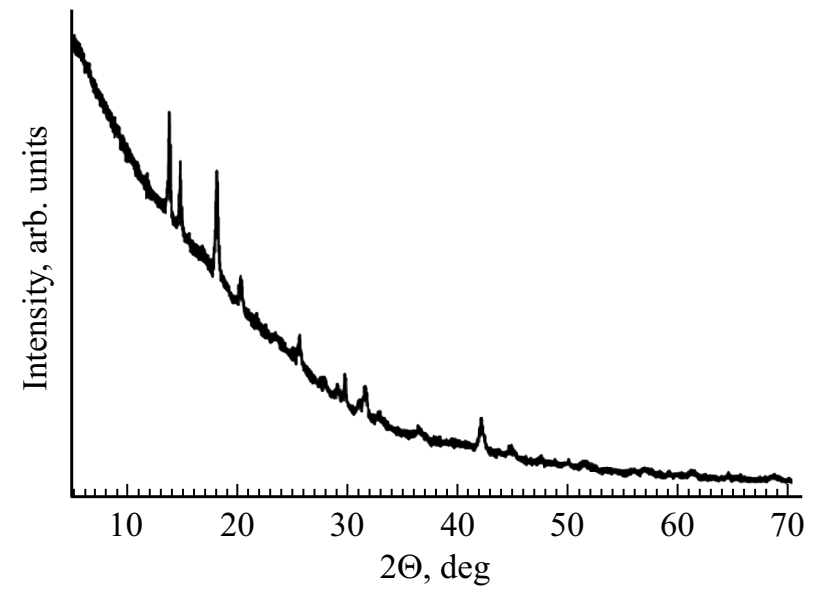

Рис. 1. Рентгенограмма $\mathrm{Al}_{0.98} \mathrm{Dy}_{0.02}(\mathrm{OH})(\mathrm{HCOO})_{2}$.

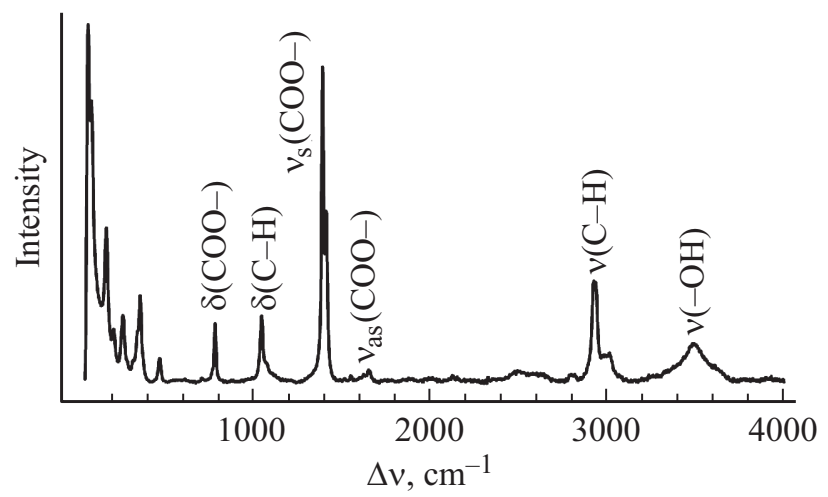

Рис. 2. КР спектр $\mathrm{Al}_{0.98} \mathrm{Dy}_{0.02}(\mathrm{OH})(\mathrm{HCOO})_{2}$.

соответствует деформационным ножничным колебаниям COO-. Асимметричным и симметричным валентным колебаниям карбоксилат-иона принадлежат частоты 1653 и $1552 \mathrm{~cm}^{-1}\left(v_{\text {as }}(\mathrm{COO}-)\right), 1412$ и $1392 \mathrm{~cm}^{-1}$ $\left(v_{\mathrm{s}}(\mathrm{COO}-)\right)$, соответственно. Слабоинтенсивная линия $3489 \mathrm{~cm}^{-1}$ связана с валентными колебаниями О-H связей металл-координированных гидроксид-ионов. Линии ниже $500 \mathrm{~cm}^{-1}$ относятся к валентным колебаниям связей $\mathrm{Al}(\mathrm{Dy})-\mathrm{O}$.

Термогравиметрический анализ был проведен для прекурсора состава $\mathrm{Al}_{0.99} \mathrm{Dy}_{0.01}(\mathrm{OH})(\mathrm{HCOO})_{2}$ (рис. 3). Разложение прекурсора при нагревании до $700^{\circ} \mathrm{C}$ происходит в два основных этапа с общей потерей массы $61.44 \%$, что соответствует потере массы (61.33\%) при образовании оксида $\left(\mathrm{Al}_{0.99} \mathrm{Dy}_{0.01}\right)_{2} \mathrm{O}_{3}$. Наблюдаемая на первом этапе (до $291^{\circ} \mathrm{C}$ ) небольшая потеря массы $(\sim 6 \%)$ обусловлена удалением воды за счет термостимулированного распада ОН-групп и образованием гипотетической фазы состава $\left(\mathrm{Al}_{0.99} \mathrm{Dy}_{0.01}\right)_{2} \mathrm{O}(\mathrm{HCOO})_{4}$, подобной $\mathrm{Al}_{2} \mathrm{O}(\mathrm{HCOO})_{4}$ [26]. Второй этап разложения характеризуется узким интервалом температур $\left(\sim 300-350^{\circ} \mathrm{C}\right)$ и более значительной потерей массы ( 55.5\%), связанной с распадом органической составляющей $\left(\mathrm{Al}_{0.99} \mathrm{Dy}_{0.01}\right)_{2} \mathrm{O}(\mathrm{HCOO})_{4}$ и выделением газооб- разных продуктов. Наблюдаемая на кривой ТГ небольшая потеря массы $(\sim 0.5 \%)$ в интервале температур $\sim 350-500^{\circ} \mathrm{C}$, вероятно, связана с удалением элементарного углерода, образующегося при термолизе прекурсора [11].

Нагреванием прекурсоров $\mathrm{Al}_{1-x} \mathrm{Dy}_{x}(\mathrm{OH})(\mathrm{HCOO})_{2}$ с $x=0.005,0.01,0.02$ и 0.025 при 700,900 и $1100^{\circ} \mathrm{C}$ на воздухе с выдержкой в течение $2 \mathrm{~h}$ при каждой температуре были синтезированы образцы номинального состава $\left(\mathrm{Al}_{1-x} \mathrm{Dy}_{x}\right)_{2} \mathrm{O}_{3}$. По данным РФА образцы оксидов, полученных путем нагревания прекурсоров при $700^{\circ} \mathrm{C}$, рентгеноаморфны. Рис. 4 демонстрирует дифрактограммы образцов $\left(\mathrm{Al}_{1-x} \mathrm{Dy}_{x}\right)_{2} \mathrm{O}_{3} \quad(x=0.005,0.01$ и $0.02)$, полученных нагреванием при $900^{\circ} \mathrm{C}$, которые были отнесены к структуре $\gamma-\mathrm{Al}_{2} \mathrm{O}_{3}$ (пр.гр. I4 $1 /$ amd, \#141) (табл. 1). Для образца с $x=0.025$ в дополнении к $\gamma$ - $\left(\mathrm{Al}_{1-x} \mathrm{Dy}_{x}\right)_{2} \mathrm{O}_{3}(98.5$ mass\%) обнаруживаются в малых

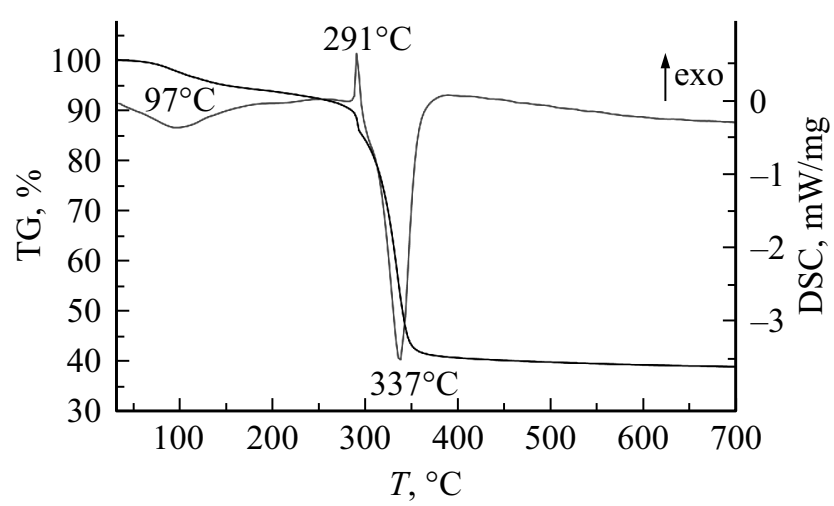

Рис. 3. Кривые ТГ и ДСК $\mathrm{Al}_{0.99} \mathrm{Dy}_{0.01}(\mathrm{OH})(\mathrm{HCOO})_{2}$.

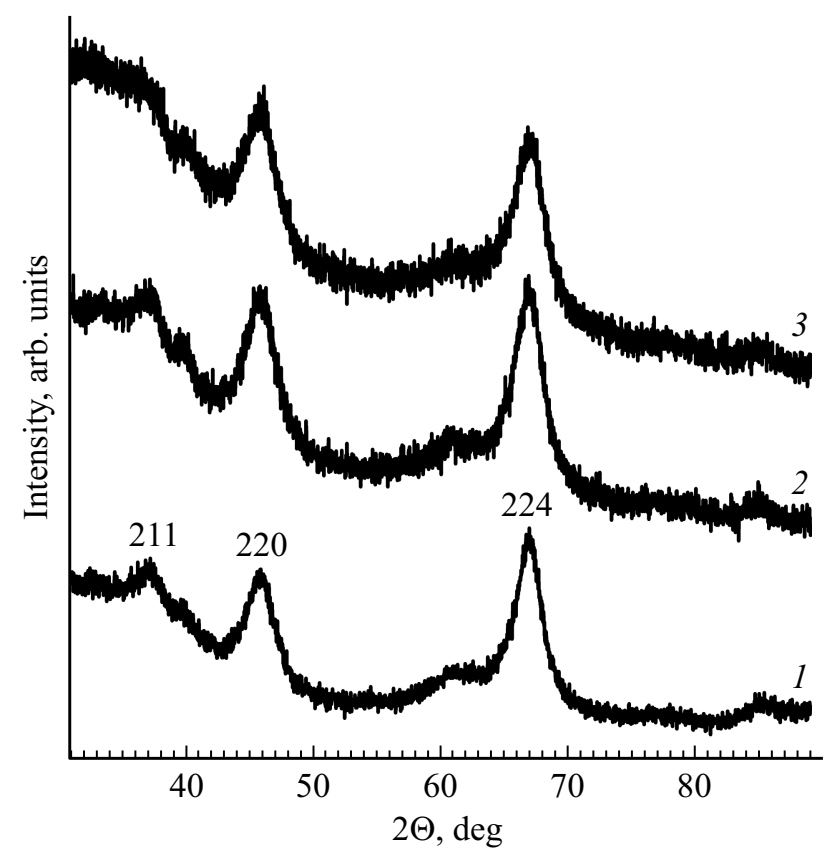

Рис. 4. Рентгенограммы $\gamma-\left(\mathrm{Al}_{1-x} \mathrm{Dy}_{x}\right)_{2} \mathrm{O}_{3}: x=0.005$ (1), 0.01 (2) и $0.02(3)$. 
Таблица 1. Параметры решетки для $\left(\mathrm{Al}_{1-x} \mathrm{Dy}_{x}\right)_{2} \mathrm{O}_{3}$, полученных нагреванием прекурсоров $\mathrm{Al}_{1-x} \mathrm{Dy}_{x}(\mathrm{OH})(\mathrm{HCOO})_{2}$ при температуре $900^{\circ} \mathrm{C}$ на воздухе

\begin{tabular}{c|c|c|c}
\hline$x$ & 0.005 & 0.01 & 0.02 \\
\hline$a, \AA$ & $5.594(2)$ & $5.636(2)$ & $5.642(2)$ \\
$c, \AA$ & $7.912(3)$ & $7.962(3)$ & $7.978(3)$ \\
$V, \AA^{3}$ & $247.6(1)$ & $252.9(1)$ & $253.9(1)$
\end{tabular}

содержаниях примесные фазы $\mathrm{DyAlO}_{3}(0.6$ mass\%) и $\mathrm{Dy}_{3} \mathrm{Al}_{5} \mathrm{O}_{12}$ (0.9 mass\%). Образцы, полученные отжигом прекурсоров при температуре $1100^{\circ} \mathrm{C}$, также неоднофазны. Например, в образце с $x=0.005$ помимо фазы со структурой $\gamma$ - $\mathrm{Al}_{2} \mathrm{O}_{3}$ присутствует $\alpha$-модификация $\mathrm{Al}_{2} \mathrm{O}_{3}$ (10.1 mass \%), а в образце с $x=0.02$ помимо того обнаружены небольшие количества $\mathrm{DyAlO}_{3}$ (1.1 mass\%). Таким образом, можно заключить, что в результате нагревания прекурсоров $\mathrm{Al}_{1-x} \mathrm{Dy}_{x}(\mathrm{OH})(\mathrm{HCOO})_{2}$, где $0.005 \leq x \leq 0.02$, при температуре $900^{\circ} \mathrm{C}$ имеет место формирование твердых растворов $\left(\mathrm{Al}_{1-x} \mathrm{Dy}_{x}\right)_{2} \mathrm{O}_{3}$ со структурой $\gamma-\mathrm{Al}_{2} \mathrm{O}_{3}$. После нагревания до $1100^{\circ} \mathrm{C}$ наблюдается частичное превращение оксида со структурой $\gamma-\mathrm{Al}_{2} \mathrm{O}_{3}$ в оксид со структурой $\alpha-\mathrm{Al}_{2} \mathrm{O}_{3}$. Ранее нами было показано, что в результате нагревания $\mathrm{Al}(\mathrm{OH})(\mathrm{HCOO})_{2}$ на воздухе образование $\gamma-\mathrm{Al}_{2} \mathrm{O}_{3}$ происходит уже при $750^{\circ} \mathrm{C}$, а его превращение в $\alpha-\mathrm{Al}_{2} \mathrm{O}_{3}$ начинается при $950^{\circ} \mathrm{C}[11]$. Следовательно, допирование ионами $\mathrm{Dy}^{3+}$ оказывает существенное влияние на структуру матрицы оксида алюминия, приводя к росту температуры фазового перехода $\gamma \rightarrow \alpha$ [14]. Атомы алюминия в оксиде $\gamma-\mathrm{Al}_{2} \mathrm{O}_{3}$ со структурой шпинели $\square_{2(2 / 3)} \mathrm{Al}_{21(1 / 3)} \mathrm{O}_{32}$ $(\square=\mathrm{Al}$ вакансии) находятся в октаэдрическом и тетраэдрическом окружении [26]. В октаэдрических позициях в структуре дефектной шпинели $\gamma-\mathrm{Al}_{2} \mathrm{O}_{3}$ располагаются катионные вакансии [27-29]. Ионы $\mathrm{Dy}^{3+}$ не имеют координационного числа ниже шести, поэтому могут замещать алюминий $\left(\mathrm{Al}^{3+}(\mathrm{VI}) 0.535 \AA\right.$ [16]) только в октаэдрических позициях в $\gamma-\mathrm{Al}_{2} \mathrm{O}_{3}$ [14].

В предыдущих работах нами уже было установлено, что способ термообработки прекурсора $\mathrm{Al}(\mathrm{OH})(\mathrm{HCOO})_{2}$ оказывает существенное влияние на эмиссионные характеристики конечного продукта [11-14]. Полученный термолизом прекурсора $\mathrm{Al}(\mathrm{OH})(\mathrm{HCOO})_{2}$ на воздухе оксид алюминия демонстрирует голубую люминесценцию с максимумом $\sim 450 \mathrm{~nm}$, появление которой обусловлено собственными дефектами матрицы оксида алюминия и/или остаточным углеродом прекурсора. На рис. 5 приведен спектр возбуждения $\gamma$ - $\left(\mathrm{Al}_{0.995} \mathrm{Dy}_{0.005}\right)_{2} \mathrm{O}_{3}$ при длине волны $572 \mathrm{~nm}$. Узкие линии относятся к электронным переходам с основного уровня ${ }^{6} \mathrm{H}_{15 / 2}$ на более высокие энергетические уровни иона $\mathrm{Dy}^{3+}:{ }^{4} \mathrm{~F}_{3 / 2}(295 \mathrm{~nm}),{ }^{6} \mathrm{P}_{3 / 2}$ $(325 \mathrm{~nm}),{ }^{6} \mathrm{P}_{7 / 2}(350 \mathrm{~nm}),{ }^{6} \mathrm{P}_{5 / 2}(365 \mathrm{~nm}),{ }^{4} \mathrm{I}_{13 / 2}(386 \mathrm{~nm})$, ${ }^{4} \mathrm{~F}_{7 / 2} \quad(426 \mathrm{~nm})$ и ${ }^{4} \mathrm{I}_{15 / 2} \quad(457 \mathrm{~nm})$, соответственно. Самая интенсивная линия наблюдается при $350 \mathrm{~nm}$

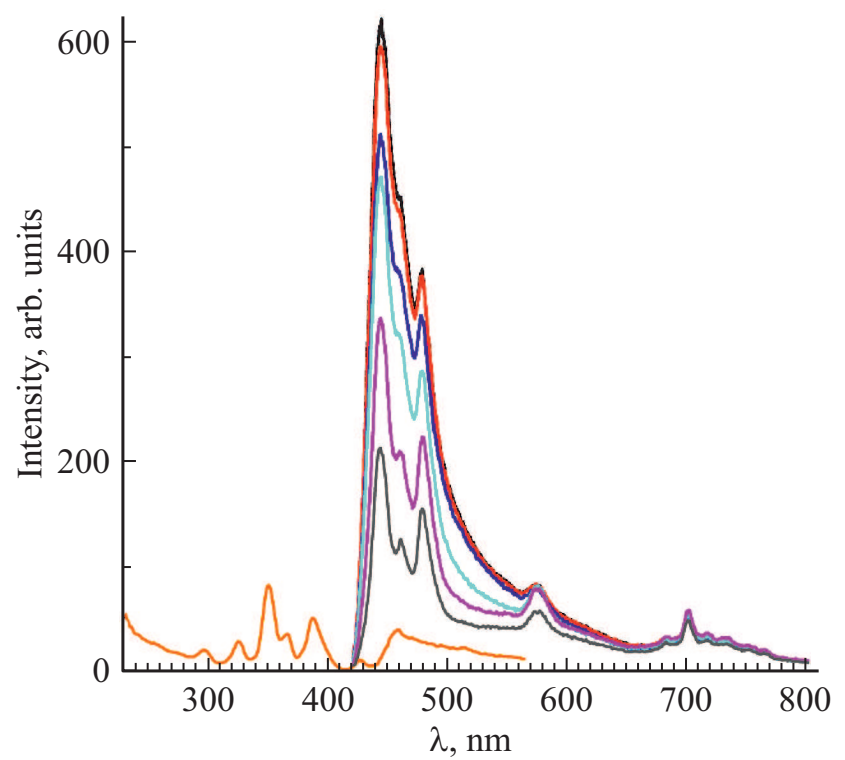

Рис. 5. Спектр возбуждения $(\lambda=573 \mathrm{~nm}$ (оранжевый) и спектры эмиссии $(\lambda=350 \mathrm{~nm})$ продуктов термолиза прекурсоров $\mathrm{Al}_{1-x} \mathrm{Dy}_{x}(\mathrm{OH})(\mathrm{HCOO})_{2}$ при различных температурах отжига на воздухе: $x=0.005$ при $700^{\circ} \mathrm{C}$ (черный), $x=0.005$ при $900^{\circ} \mathrm{C}$ (красный), $x=0.005$ при $1100^{\circ} \mathrm{C}$ (синий), $x=0.02$ при $700^{\circ} \mathrm{C}$ (голубой), $x=0.02$ при $900^{\circ} \mathrm{C}$ (розовый) и $x=0.02$ при $1100^{\circ} \mathrm{C}$ (серый).

и соответствует переходу ${ }^{6} \mathrm{H}_{15 / 2} \rightarrow{ }^{6} \mathrm{P}_{7 / 2}$. Спектры эмиссии всех полученных образцов при УФ-возбуждении $(\lambda=350 \mathrm{~nm})$ состоят из широких полос с максимумом в синей области спектра, представляющих собой наложение эмиссионных линий, связанных с собственными дефектами матрицы и $\mathrm{f}-\mathrm{f}$ переходами в ионах $\mathrm{Dy}^{3+}$ (рис. 5). На спектре представлены следующие линии люминесценции принадлежащие $\mathrm{f}-\mathrm{f}$-переходам иона $\mathrm{Dy}^{3+}:{ }^{4} \mathrm{G}_{11 / 2} \rightarrow{ }^{6} \mathrm{H}_{15 / 2} \quad(445 \mathrm{~nm})$, ${ }^{4} \mathrm{I}_{15 / 2} \rightarrow{ }^{6} \mathrm{H}_{15 / 2} \quad(458 \mathrm{~nm}), \quad{ }^{4} \mathrm{~F}_{9 / 2} \rightarrow{ }^{6} \mathrm{H}_{15 / 2} \quad(477 \mathrm{~nm})$, ${ }^{4} \mathrm{~F}_{9 / 2} \rightarrow{ }^{6} \mathrm{H}_{13 / 2} \quad(572 \mathrm{~nm}), \quad{ }^{4} \mathrm{~F}_{9 / 2} \rightarrow{ }^{6} \mathrm{H}_{11 / 2} \quad(681 \mathrm{~nm})$, ${ }^{4} \mathrm{~F}_{9 / 2} \rightarrow{ }^{6} \mathrm{H}_{9 / 2}+{ }^{6} \mathrm{~F}_{11 / 2} \quad(699 \mathrm{~nm}), \quad{ }^{4} \mathrm{~F}_{9 / 2} \rightarrow{ }^{6} \mathrm{H}_{7 / 2}+{ }^{6} \mathrm{~F}_{9 / 2}$ $(764 \mathrm{~nm})$. Можно отметить существенное изменение интенсивности люминесценции в зависимости от концентрации диспрозия и температуры отжига прекурсора (рис. 5). С увеличением температуры отжига прекурсора происходит уменьшение интенсивности эмиссии, наблюдается тушение люминесценции матрицы оксида алюминия. Аналогичная зависимость интенсивности люминесценции от температуры отжига прекурсоров наблюдалась для продуктов термолиза $\mathrm{Al}(\mathrm{OH})(\mathrm{HCOO})_{2}$, полученных на воздухе и в гелии и связана со структурными изменениями матрицы оксида алюминия [11]. Допирование диспрозием оксида алюминия также приводит к подавлению голубой люминесценции. Однако, если проследить за изменением интенсивности линий, относящихся к переходам иона диспрозия, то можно заметить, что тушение люминесценции наблюдается лишь для образца, полученного термолизом прекурсора 
$\mathrm{Al}_{0.98} \mathrm{Dy}_{0.02}(\mathrm{OH})(\mathrm{HCOO})_{2}$ при $1100^{\circ} \mathrm{C}$. При увеличении концентрации диспрозия расстояние между ионами активатора становится меньше, что приводит к более высокой вероятности безызлучательного переноса энергии. В образце оксида алюминия полученного при $1100^{\circ} \mathrm{C}$ присутствуют примесные фазы $\left(\alpha-\mathrm{Al}_{2} \mathrm{O}_{3}\right.$ и $\left.\mathrm{DyAlO}_{3}\right)$, которые также могут оказывать влияние на тушении люминесценции. Для остальных образцов интенсивности линии, отнесенные к переходам ${ }^{4} \mathrm{~F}_{9 / 2} \rightarrow{ }^{6} \mathrm{H}_{13 / 2} \quad(572 \mathrm{~nm}), \quad{ }^{4} \mathrm{~F}_{9 / 2} \rightarrow{ }^{6} \mathrm{H}_{11 / 2} \quad(681 \mathrm{~nm})$, ${ }^{4} \mathrm{~F}_{9 / 2} \rightarrow{ }^{6} \mathrm{H}_{9 / 2}+{ }^{6} \mathrm{~F}_{11 / 2} \quad(699 \mathrm{~nm}), \quad{ }^{4} \mathrm{~F}_{9 / 2} \rightarrow{ }^{6} \mathrm{H}_{7 / 2}+{ }^{6} \mathrm{~F}_{9 / 2}$ $(764 \mathrm{~nm})$ не сильно зависят от концентрации диспрозия. Также не наблюдается никакого сдвига максимумов интенсивностей в сторону большей или меньшей длины волны при изменении концентрации ионов $\mathrm{Dy}^{3+}$.

Кривые затухания (рис. 6) для $\gamma-\left(\mathrm{Al}_{1-x} \mathrm{Dy}_{x}\right)_{2} \mathrm{O}_{3}$ с $x=0.005,0.01$ и 0.02 были зарегистрированы при длине волны возбуждения $350 \mathrm{~nm}$ и длине волны излучения $479 \mathrm{~nm}$ и могут быть аппроксимированы двойной экспоненциальной функцией. Рассчитанные средние времена жизни для $\gamma$ - $\left(\mathrm{Al}_{1-x} \mathrm{Dy}_{x}\right)_{2} \mathrm{O}_{3}$ равны $0.6 \mathrm{~ms}(x=0.005)$, $0.52 \mathrm{~ms}(x=0.01)$ и $0.51 \mathrm{~ms}(x=0.02)$, и близки к значениям, полученным для различных соединений, допированных диспрозием [30-32]. Двойной экспоненциальный профиль кривых затухания, а также уменьшение времени жизни с концентрацией диспрозия могут быть объяснены как передачей энергии от алюминиевой матрицы к ионам $\mathrm{Dy}^{3+}$, процессами кросс-релаксации между соседними ионами $\mathrm{Dy}^{3+}$, так и неоднородным распределением люминесцентных центров в алюминиевой матрице [30,31].

Параметры, характеризующие цвет излучения исследуемых соединений, были рассчитаны из спектров люминесценции при длине волны возбуждения $350 \mathrm{~nm}$ и представлены в табл. 2. Координаты цвет-

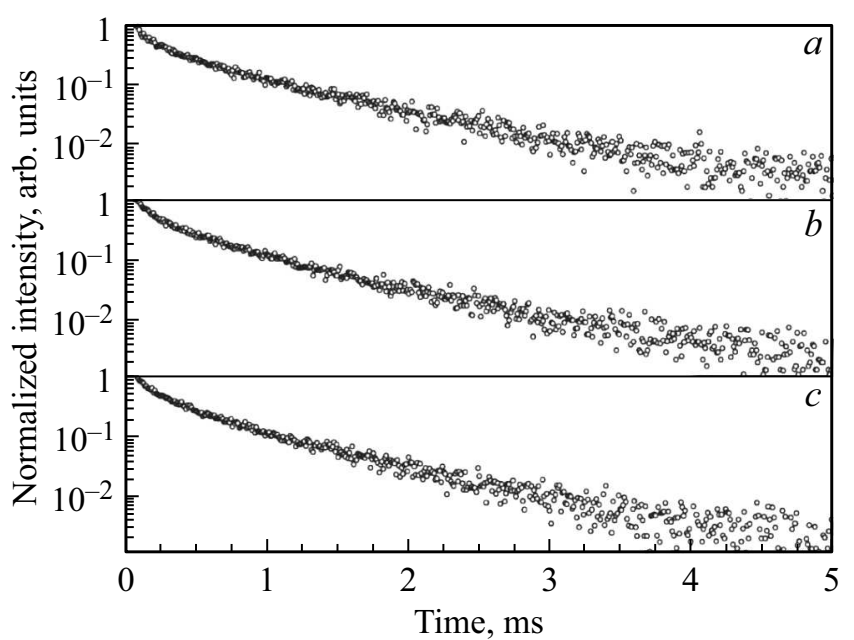

Рис. 6. Кривые затухания люминесценции продуктов термолиза прекурсоров $\mathrm{Al}_{1-x} \mathrm{Dy}_{x}(\mathrm{OH})(\mathrm{HCOO})_{2}$ при $x=0.005(a)$, $x=0.01(b)$ и $x=0.02(c)$, измеренные при $\lambda_{\mathrm{ex}}=350 \mathrm{~nm}$ и $\lambda_{\mathrm{em}}=479 \mathrm{~nm}$.
Таблица 2. Цветовые координаты $(x, y)$ продуктов термолиза прекурсоров $\mathrm{Al}_{1-x} \mathrm{Dy}_{x}(\mathrm{OH})(\mathrm{HCOO})_{2}$ при различных температурах на воздухе

\begin{tabular}{c|r|c|c|c|c}
\hline$x$ & $T,{ }^{\circ} \mathrm{C}$ & $x$ & $y$ & Цвет излучения & Чистота цвета, \% \\
\hline \multirow{4}{*}{0.005} & 700 & 0.19 & 0.17 & голубой & 59.31 \\
\cline { 2 - 6 } & 900 & 0.19 & 0.17 & голубой & 59.31 \\
\cline { 2 - 6 } & 1100 & 0.20 & 0.18 & голубой & 55.37 \\
\hline \multirow{4}{*}{0.02} & 700 & 0.20 & 0.17 & фиолетово-синий & 57.51 \\
\cline { 2 - 6 } & 900 & 0.23 & 0.18 & фиолетово-синий & 50.29 \\
\cline { 2 - 5 } & 1100 & 0.24 & 0.22 & белый & 39.65
\end{tabular}

ности $(x, y)$ люминофора, полученного нагреванием прекурсора $\mathrm{Al}_{0.98} \mathrm{Dy}_{0.02}(\mathrm{OH})(\mathrm{HCOO})_{2}$ при $1100^{\circ} \mathrm{C}$ составляют $(0.24,0.22)$ и располагаются на диаграмме, предложенной K.L. Kelly в области белого цвета [15]. Чистота цвета образцов, рассчитанная по координатам цветности белого источника света и доминирующей длины волны, $\lambda=443 \mathrm{~nm}$ [33], варьирует от $\sim 60$ до $\sim 40 \%$ (табл. 2).

Существенное изменение эмиссии люминофора с ростом температуры ставит под сомнение его технологические перспективы, поэтому оценка термической стабильности является одной из обязательных характеристик при исследовании новых излучающих материалов. Для соединений, рассматриваемых для применения в видимом спектральном диапазоне, считается допустимым сохранение достаточной эффективности эмиссии при температурах выше $150^{\circ} \mathrm{C}$ [34]. Соответственно температура (температура термического тушения $T_{50 \%}$ ), при которой соединение демонстрирует половину своей интенсивности излучения, зарегистрированной при комнатной температуре, является пороговым значением, которое определяет будущие перспективы соединения. Спектры люминесценции $\left(\lambda_{\mathrm{ex}}=350 \mathrm{~nm}\right)$ соединения $\gamma-\left(\mathrm{Al}_{0.995} \mathrm{Dy}_{0.005}\right)_{2} \mathrm{O}_{3}$, измеренные в широком температурном интервале, приведены на рис. 7. Постепенный нагрев образца до $150^{\circ} \mathrm{C}$ сопровождается уменьшением интенсивности эмиссионных линий в голубом спектральном диапазоне, связанных с собственными дефектами матрицы оксида алюминия, тогда как интенсивность линии излучения в длинноволновом диапазоне, соответствующих $\mathrm{f}-\mathrm{f}$ переходам в ионах диспрозия, остается почти неизменной. При нагреве порошка до $150^{\circ} \mathrm{C}$, интенсивность люминесценции составляет $68 \%$ от первоначального значения. Рассчитанная зависимость $I / I_{R T}=f(T)$, представленная на вставке к рис. 7, описывается модифицированным уравнением Аррениуса [35], и позволяет достаточно точно определить температуру термического тушения. Соединение демонстрируют высокую термическую стабильность эмиссии: рассчитанное значение $T_{50 \%}$ составляет $245^{\circ} \mathrm{C}$, а координаты цветно- 

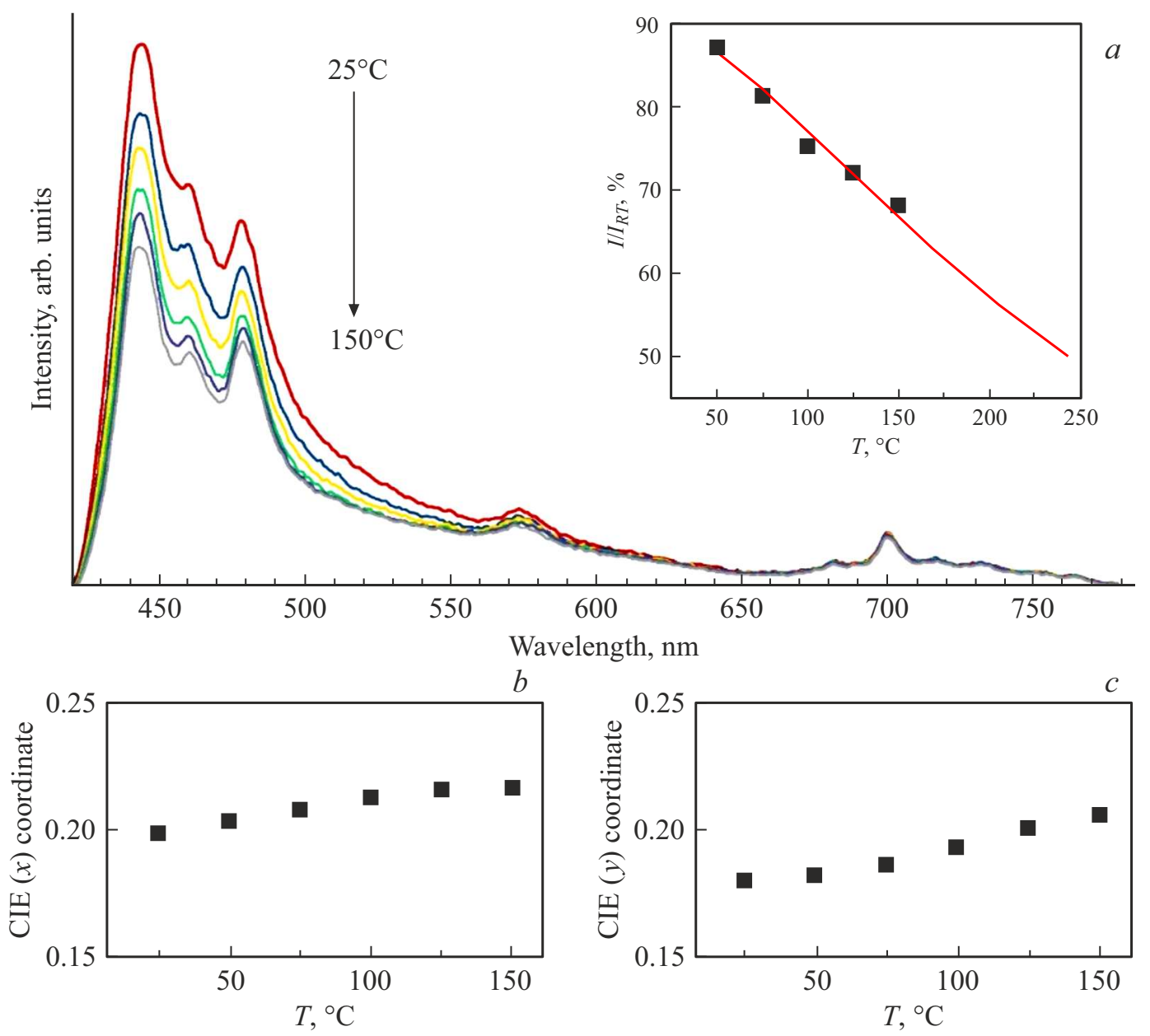

Рис. 7. Спектры люминесценции $\left(\lambda_{\mathrm{ex}}=350 \mathrm{~nm}\right) \mathrm{Al}_{0.995} \mathrm{Dy}_{0.005}(\mathrm{OH})(\mathrm{HCOO})_{2}$, измеренные при различной температуре нагрева $(a)$; температурные зависимости интегральной интенсивности люминесценции (вставка) и значений цветовых координат $(x, y)(b, c)$.

сти остаются неизменными во всем зарегистрированном температурном интервале (рис. 7).

\section{4. Заключение}

Люминофоры на основе оксида алюминия допированного диспрозием $\mathrm{Al}_{2} \mathrm{O}_{3}: \mathrm{Dy}^{3+}$ были получены термическим разложением на воздухе прекурсоров $\mathrm{Al}_{1-x} \mathrm{Dy}_{x}(\mathrm{OH})(\mathrm{HCOO})_{2}$. Из анализа структурных данных следует, что при термолизе прекурсоров оксиды $\gamma-\left(\mathrm{Al}_{1-x} \mathrm{Dy}_{x}\right)_{2} \mathrm{O}_{3} \quad(x=0.005,0.01,0.02)$ образуются только при температуре $900^{\circ} \mathrm{C}$. Широкая и интенсивная люминесценция синтезируемых образцов в видимом диапазоне с максимумами в синей области обусловлена перекрытием эмиссионных линий матрицы $\mathrm{Al}_{2} \mathrm{O}_{3}$ и спектра иона $\mathrm{Dy}^{3+}$, вызванного $\mathrm{f}-\mathrm{f}$ переходами. Согласно цветовым координатам, синтезируемые оксиды обладают разным по цвету излучением в зависимости от концентрации диспрозия и температуры термолиза прекурсора. Учитывая высокую термическую стабильность излучения, оксиды $\mathrm{Al}_{2} \mathrm{O}_{3}: \mathrm{Dy}^{3+}$ становятся очень привлекательными соединениями для использования в качестве люминофоров холодного свечения.

\section{Финансирование работы}

Работа выполнена в соответствии с госзаданием Института химии твердого тела УрО РАН и планами НИР в сфере фундаментальных научных исследований (№ AAAA-A19-119031890025-9).

\section{Конфликт интересов}

Авторы заявляют, что у них нет конфликта интересов.

\section{Список литературы}

[1] G.B. Nair, H.C. Swart, S.J. Dhoble. Prog. Mater. Sci. 109, 100622 (2020).

[2] S. Nakamura. J. Vac. Sci. Technol. A 13, 705 (1995).

[3] D. Adachi, H. Haze, H. Shirahase, T. Toyama, H. Okamoto. J. Non-Cryst. Solids 352, 1628 (2006).

[4] J. Liao, B. Qiu, H. Wen, J. Chen, W. You, L. Liu. J. Alloys Compd. 487, 758 (2009). 
[5] V.N.K.B. Adusumalli, S. Sarkar, V. Mahalingam. Chem. Phys. Chem. 16, 2312 (2015).

[6] K.B. Kim, Y.I. Kim, H.G. Chun, T.Y. Cho, J.S. Jung, J.G. Kang. Chem. Mater. 14, 5045 (2002).

[7] L. Ye, X. Peng, S. Zhang, Y. Wang, W. Chang. J. Rare Earths 32, 1109 (2014).

[8] P. Boolchand, K.C. Mishra, M. Raukas, A. Ellens, P.C. Schmidt. Phys. Rev. B 66, 134429 (2002).

[9] X. Zhang, J. Song, C. Zhou, L. Zhou, M. Gong. J. Lumin. 149, 69 (2014).

[10] F. Lu, L. Bai, Z. Yang, X. Han. Mater. Lett. 151, 9 (2015).

[11] V.N. Krasil'nikov, I.V. Baklanova, V.P. Zhukov, N.I. Medvedeva, A.P. Tyutyunnik, R.F. Samigullina, O.I. Gyrdasova, M.A. Melkozerova. J. Alloys Compd. 698, 1102 (2017).

[12] M.A. Melkozerova, O.I. Gyrdasova, I.V. Baklanova, E.V. Vladimirova, E.V. Zabolotskaya, V.N. Krasil'nikov. Mendeleev Commun. 28, 668 (2018).

[13] I.V. Baklanova, V.N. Krasil'nikov, A.P. Tyutyunnik, A.N. Enyashin, Ya.V. Baklanova, O.I. Gyrdasova, R.F. Samigullina, E.G. Vovkotrub. Spectrochim. Acta A 227, 117658 (2020).

[14] I.V. Baklanova, V.N. Krasil'nikov, A.P. Tyutyunnik, Ya.V. Baklanova. J. Solid State Chem. 292, 121699 (2020).

[15] K.L. Kelly. J. Opt. Soc. Am. 33, 627 (1943).

[16] R.D. Shannon. Acta Cryst. A, 32, 751 (1976).

[17] G.B. Nair, S.J. Dhoble. RSC Adv. 5, 49235 (2015).

[18] T. Ishizaka, Y. Kurokawa. J. Lumin. 92, 57 (2001).

[19] S. Kumar, R. Prakash, V. Kumar. Funct. Mater. Lett. 8, 1550061 (2015).

[20] N. Ishiwada, E. Fujii, T. Yokomori. J. Lumin. 196, 492 (2018).

[21] R. Martínez-Martínez, S. Rivera, E. Yescas-Mendoza, E. Álvarez, C. Falcony, U. Caldiño. Opt. Mater. 33, 1320 (2011).

[22] S. Stojadinović, A. Cirić. J. Lumin. 226, 117403 (2020).

[23] B.H. Toby. J. Appl. Crystallogr. 34, 210 (2001).

[24] A.C. Larson, R.B. Von Dreele. General Structure Analysis System (GSAS). Los Alamos, NM (2004). Los Alamos National Laboratory Report LAUR 86-748.

[25] V.N. Krasil'nikov, A.P. Tyutyunnik, I.V. Baklanova, A.N. Enyashin, I.F. Berger, V.G. Zubkov. CrystEngComm. 20, 2741 (2018).

[26] K. Sohlberg, S.J. Pennycook, S.T. Pantelides. J. Am. Chem. Soc. 121, 7493 (1999).

[27] J.M.A. Caiut, L. Bazin, R. Mauricot, H. Dexpert, S.J.L. Ribeiro, J. Dexpert-Ghys. J. Non-Cryst. Solids 354, 4860 (2008).

[28] A. Rastorguev, M. Baronskiy, A. Zhuzhgov, A. Kostyukov, O. Krivoruchko, V. Snytnikov. RSC Adv. 5, 5686 (2015).

[29] G. Gutierrez, A. Taga, B. Johansson. Phys. Rev. B 65, 012101 (2001).

[30] J. Zhang, Q.Guo, L. Liao, Y. Wang, M. He, H. Ye, L. Mei, H. Liu, T. Zhou, B. Ma. RSC Adv. 8, 38883 (2018).

[31] Z. An, X. Xiao, J. Yu, D. Mao, G. Lu. RSC Adv. 5, 52533 (2015).

[32] U. Fawad, H.J. Kim, S. Khan, M. Khan, L. Ali. Solid State Sci. 62, 1 (2016).

[33] J.S. Kumar, K. Pavani, A.M. Babu, N.K. Giri, S.B. Rai, L.R. Moorthy. J. Lumin., 130, 1916 (2010).

[34] J. Li, J. Yan, D. Wen, W. Ullah Khan, J. Shi, M. Wu, Q. Su, P.A. Tanner. J. Mater. Chem. C 4, 8611, (2016).

[35] V. Bachmann, C. Ronda, O. Oeckler, W. Schnick, A. Meijerink. Chem. Mater. 21, 316 (2009).

Редактор Т.Н. Василевская 